\title{
Higher glucocorticoid replacement doses are associated with increased mortality in patients with pituitary adenoma
}

\author{
Casper Hammarstrand1, Oskar Ragnarsson', Tobias Hallén², Eva Andersson³, \\ Thomas Skoglund², Anna G Nilsson', Gudmundur Johannsson ${ }^{1, *}$ and \\ Daniel S Olsson ${ }^{1, *}$ \\ 'Department of Endocrinology, Institute of Medicine, Sahlgrenska Academy, University of Gothenburg and \\ Sahlgrenska University Hospital, Göteborg, Sweden, ${ }^{2}$ Department of Neurosurgery, Sahlgrenska University \\ Hospital, Göteborg, Sweden, and ${ }^{3}$ Department of Occupational and Environmental Medicine, Institute of \\ Medicine, Sahlgrenska Academy, University of Gothenburg and Sahlgrenska University Hospital, \\ Gothenburg, Sweden \\ *(G Johannsson and D S Olsson contributed equally to this work)
}

Correspondence should be addressed to D S Olsson Email

daniel.olsson@gu.se

\begin{abstract}
Objective: Patients with secondary adrenal insufficiency (Al) have an excess mortality. The objective was to investigate the impact of the daily glucocorticoid replacement dose on mortality in patients with hypopituitarism due to nonfunctioning pituitary adenoma (NFPA).

Methods: Patients with NFPA were followed between years 1997 and 2014 and cross-referenced with the National Swedish Death Register. Standardized mortality ratio (SMR) was calculated with the general population as reference and Cox-regression was used to analyse the mortality.

Results: The analysis included 392 patients (140 women) with NFPA. Mean \pm s.D. age at diagnosis was $58.7 \pm 14.6$ years and mean follow-up was $12.7 \pm 7.2$ years. Al was present in 193 patients, receiving a mean daily hydrocortisone equivalent (HCeq) dose of $20 \pm 6 \mathrm{mg}$. SMR $(95 \%$ confidence interval $(\mathrm{CI}))$ for patients with Al was similar to that for patients without, $0.88(0.68-1.12)$ and $0.87(0.63-1.18)$ respectively. SMR was higher for patients with a daily HCeq dose of $>20 \mathrm{mg}(1.42(0.88-2.17))$ than that in patients with a daily HCeq dose of $20 \mathrm{mg}(0.71(0.49-0.99)), P=0.017$. In a Cox-regression analysis, a daily HCeq dose of $>20 \mathrm{mg}$ was independently associated with a higher mortality (HR: 1.88 (1.06-3.33)). Patients with daily HCeq doses of $\leq 20 \mathrm{mg}$ had a mortality risk comparable to patients without glucocorticoid replacement and to the general population.

Conclusion: Patients with NFPA and Al receiving more than $20 \mathrm{mg} \mathrm{HCeq}$ per day have an increased mortality. Our data also show that mortality in patients substituted with $20 \mathrm{mg} \mathrm{HCeq}$ per day or less is not increased.
\end{abstract}

\section{Introduction}

Patients with hypopituitarism have increased morbidity and mortality $(1,2)$. Along with factors such as young age at diagnosis, female gender, underlying pituitary disease and pituitary radiation therapy, it has been suggested that the current hormone replacement regimes may contribute to the adverse outcome $(2,3,4,5,6,7,8)$.
() 2017 European Society of Endocrinology Printed in Great Britain
The traditional glucocorticoid (GC) replacement dose used in patients with adrenal insufficiency (AI) is considerably higher than the estimated endogenous cortisol production rate in healthy subjects $(10-15 \mathrm{mg} /$ day) $(9,10)$. Excess GC exposure over time may contribute to an increased risk of adverse metabolic profile and 
premature death $(4,11,12,13)$. Previous studies have shown increased mortality in hypopituitary patients with acromegaly using daily hydrocortisone (HC) replacement doses of $\geq 25 \mathrm{mg}$ (12) and in patients with NFPA with daily HC doses of $\geq 30 \mathrm{mg}$ (13). HC clearance depends largely on body weight and a weight-adjusted GC replacement dose has therefore been suggested (14). Zueger et al. demonstrated that body weight-adapted $\mathrm{HC}$ doses of $\geq 0.35 \mathrm{mg} / \mathrm{kg}$ are associated with increased mortality (4). Our group has, in a previous study, shown that patients with hypopituitarism and AI using a daily hydrocortisone dose $\geq 20 \mathrm{mg}$ per day had a worse cardiometabolic risk profile than hypopituitary patients without GC replacement therapy (11).

The aim of this study was to investigate the impact of GC dose on mortality in a large and unselected population of NFPA patients. Our main hypothesis was that patients receiving daily $\mathrm{HC}$ doses higher than $20 \mathrm{mg}$ have the worst outcome.

\section{Subjects and methods}

\section{Study design}

This was a cohort study including all patients treated or followed for NFPA in the western region of Sweden between Jan 1, 1997 and Dec 31, 2011. To be certain that all patients with NFPA from the western region of Sweden were included, we also searched the Swedish National Patient Register (Patient Register). The Patient Register achieved a national coverage in 1987 and contains information from every patient visit within the Swedish hospital system using a unique identification number.

Medical charts for all patients were manually reviewed to ensure that the diagnosis of NFPA was correct and in order to collect information on medical history and clinical characteristics, including hormonal replacement therapy. In total, 405 patients with a confirmed NFPA were identified. Of these, 13 patients were excluded due to GC treatment for non-endocrine diseases (ten of these patients died during the study period). Thus, 392 patients were included in the final analysis.

For each patient start of follow-up was defined as either the time point when NFPA was diagnosed or the start of the study (January 1, 1987). All patients were followed to Dec 31, 2014 or until death. Current replacement therapy was defined as the treatment the patients received at their last clinical visit before the end of study. Information on mortality was obtained from the Swedish National Cause of Death Register.

Secondary AI was diagnosed according to local clinical practice. The majority of patients have, however, been diagnosed and followed at Sahlgrenska University Hospital, using morning serum cortisol measurements and a Synacthen test. If inconclusive, these tests were followed by an insulin tolerance test.

For patients with secondary AI, and not receiving $\mathrm{HC}$ ( $n=7$, all receiving cortisone acetate), a HC equivalent (HCeq) dose was calculated $(15,16)$. Patients with GC replacement were divided into three groups according to their daily HCeq dose $(<20,20$ or $>20 \mathrm{mg} /$ day $)$. The patients were also grouped according to their daily HCeq dose per kg body weight $(\leq 0.25,>0.25-0.30$ and $>0.30$ $0.55 \mathrm{mg} / \mathrm{kg} /$ day).

\section{Ethics}

The study was approved by the Regional Ethical Review Board in Gothenburg, Sweden, and by the National Board of Health and Welfare, Sweden.

\section{Statistics}

Person-years at risk were calculated from study inclusion to death, or end of study, and stratified according to gender, 5-year age groups and 1-year calendar periods. The expected number of deaths for each stratum was calculated using the general Swedish population for every calendar year and 5-year age group as reference. The observed number of deaths among patients with NFPA was compared to that expected by standardised mortality ratios (SMRs). Ninety-five percent confidence intervals (CIs) were calculated assuming a Poisson distribution of the observed numbers. Subgroup analyses for absolute daily HCeq dose and daily HCeq dose per kg were performed. SMRs for nonoverlapping subgroups were compared to each other (17).

Multivariable Cox-regression models were used to calculate hazard ratio (HR) of mortality, adjusted for: age at the start of the study, gender and treatment with radiotherapy, as well as absolute- or weight-adjusted HCeq dosage. HR was also calculated for patients with secondary AI and compared to patients with intact hypothalamic-pituitary-adrenal function. The level of significance was set to $P<0.05$. IBM SPSS (version 24) and STATA SE (version 14) software was used to perform the statistical analyses. 
Table 1 Characteristics of patients with non-functioning pituitary adenoma included in the study.

\begin{tabular}{|c|c|}
\hline & Total $(n=392)$ \\
\hline \multicolumn{2}{|l|}{ Gender, $n(\%)$} \\
\hline Men & $252(64)$ \\
\hline Women & $140(36)$ \\
\hline Age at diagnosis, years, mean \pm s.D. & $58.7 \pm 14.6$ \\
\hline Men, mean \pm S.D. & $58.9 \pm 13.9$ \\
\hline Women, mean \pm S.D. & $58.3 \pm 15.9$ \\
\hline Hypopituitarism, $n(\%)$ & $313(80)$ \\
\hline Diabetes insipidus, $n$ (\%) & $46(12)$ \\
\hline \multicolumn{2}{|l|}{ Hormonal replacement, $n(\%)$} \\
\hline - None & $75(19)$ \\
\hline - Levothyroxine & $272(69)$ \\
\hline - Glucocorticoids ${ }^{a}$ & $193(49)$ \\
\hline - Sex steroids & $186(47)$ \\
\hline - Growth hormone & $160(41)$ \\
\hline Mean follow-up time, years (range) & $12.7(0.1-28)$ \\
\hline Patient-years at risk in the study & 4961 \\
\hline Treatment with surgery, $n(\%)$ & $287(73)$ \\
\hline Treatment with radiotherapy, $n(\%)$ & $78(20)$ \\
\hline
\end{tabular}

Patients treated with glucocorticoids due to non-endocrine chronic disorders were excluded $(n=13)$.

ancludes replacement with hydrocortisone $(n=186)$ and cortisone acetate $(n=7)$.

\section{Results}

\section{Patient characteristics}

In total, 392 patients with NFPA were included in the analysis, 252 men and 140 women (Table 1). The mean age at diagnosis was $58.7 \pm 14.6$ years and the mean follow-up time was $12.7 \pm 7.2$ years. Of the 392 patients, 287 (73\%) underwent surgical treatment, of whom 76 (19\%) also received pituitary radiation therapy. Two patients received treatment with radiation therapy alone, and the remainder $(n=103,26 \%)$ did not receive any targeted therapy for their NFPA.

The prevalence of growth hormone, levothyroxine, sex hormones and anti-diuretic hormone replacement therapy in the cohort are shown in Table 1 . The number of patients with any form of hypopituitarism was 313 (80\%). Secondary AI was recorded in 193 patients (49\%). The vast majority received HC $(n=186)$ and the remainder received cortisone acetate $(n=7)$. The mean \pm S.D. daily HCeq dose was $20 \mathrm{mg} \pm 6$ and the mean HCeq dose per $\mathrm{kg}$ was $0.25 \pm 0.09$. The most common dosing frequency of GC replacement was BID $(n=159)$, followed by OD $(n=27)$ or TID $(n=7)$.

\section{Mortality}

In the whole group of 392 patients, 106 deaths were recorded. The most frequent cause of death in all subgroups was diseases of the circulatory system (ICD10 Chapter 9) (Table 2). Only two patients died due to infectious diseases (ICD-10 Chapter 1). Patients with secondary AI had an SMR similar to that for patients

Table 2 Characteristics of non-functioning pituitary adenoma patients with and without glucocorticoid (GC) replacement therapy.

\begin{tabular}{|c|c|c|c|c|c|}
\hline & \multirow[b]{2}{*}{ Without GC } & \multirow[b]{2}{*}{ With GC } & \multicolumn{3}{|c|}{ With GC } \\
\hline & & & $<20 \mathrm{mg} /$ day & $20 \mathrm{mg} / \mathrm{day}$ & $>20 \mathrm{mg} / \mathrm{day}$ \\
\hline No. of patients (\%) & $199(51)$ & $193(49)$ & $43(11)$ & $113(29)$ & $37(9)$ \\
\hline Gender, men/women (\%) & $113 / 86(57 / 43)$ & $139 / 54(72 / 28)$ & $25 / 18(58 / 42)$ & $88 / 25(78 / 22)$ & $26 / 11(70 / 30)$ \\
\hline Age at diagnosis (years, mean \pm s.D.) & $57.6 \pm 15.5$ & $59.8 \pm 13.6$ & $57.6 \pm 12.7$ & $59.1 \pm 12.9$ & $64.6 \pm 15.7$ \\
\hline $\begin{array}{l}\text { Body weight at the end of follow-up } \\
(\mathrm{kg}, \text { mean } \pm \text { s.D. })\end{array}$ & $81.2 \pm 16.0$ & $84.1 \pm 18.0$ & $83.1 \pm 20.6$ & $84.9 \pm 16.3$ & $82.6 \pm 19.8$ \\
\hline $\begin{array}{l}\text { Growth hormone replacement } \\
\text { therapy (\%) }\end{array}$ & $61(31)$ & $99(51)$ & $24(56)$ & $61(54)$ & $14(38)$ \\
\hline \multicolumn{6}{|l|}{ Comorbidities, $n(\%)^{\mathrm{a}}$} \\
\hline Type 2 diabetes mellitus & $22(11)$ & $20(10)$ & $6(14)$ & $11(10)$ & $3(8)$ \\
\hline Hyperlipidaemia & $74(37)$ & $67(35)$ & $14(33)$ & $44(39)$ & $9(24)$ \\
\hline Hypertension & $107(54)$ & $111(58)$ & $20(47)$ & $73(65)$ & $18(49)$ \\
\hline \multicolumn{6}{|l|}{ Cause of death (ICD-10 Chapters), $n(\%)^{\mathrm{b}}$} \\
\hline Total number of deaths & 42 & 64 & 10 & 33 & 21 \\
\hline Neoplasms (2) & $14(33)$ & $13(20)$ & $3(30)$ & $5(15)$ & $5(24)$ \\
\hline Diseases of the nervous system (6) & $4(10)$ & $2(3)$ & $0(0)$ & $2(6)$ & $0(0)$ \\
\hline Diseases of the circulatory system (9) & $15(36)$ & $28(44)$ & $5(50)$ & $16(48)$ & $7(33)$ \\
\hline Diseases of the respiratory system (10) & $2(5)$ & $4(6)$ & $2(20)$ & $1(3)$ & $1(5)$ \\
\hline Diseases of the digestive system (11) & $2(5)$ & $4(6)$ & $0(0)$ & $2(6)$ & $2(10)$ \\
\hline $\begin{array}{l}\text { External causes of morbidity and } \\
\text { mortality (20) }\end{array}$ & $3(7)$ & $4(6)$ & $0(0)$ & $3(9)$ & $1(5)$ \\
\hline
\end{tabular}


Table 3 Standardised mortality ratio in non-functioning pituitary adenoma patients with and without glucocorticoid replacement therapy using the general population as reference.

\begin{tabular}{l}
\hline Outcome \\
\hline Analysed using HCeq dose $/ \mathrm{kg}$ \\
Patients without HC \\
Patients with $>0-0.25 \mathrm{mg} / \mathrm{kg}$ \\
Patients with $>0.25-0.30 \mathrm{mg} / \mathrm{kg}^{\text {a }}$ \\
Patients with $>0.30-0.55 \mathrm{mg} / \mathrm{kg}^{\mathrm{a}}$ \\
Analysed using HCeq dose $/ \mathrm{day}$ \\
Patients without HCeq \\
Patients with $<20 \mathrm{mg}$ \\
Patients with $20 \mathrm{mg}^{\mathrm{b}}$ \\
Patients with $>20 \mathrm{mg}^{\mathrm{b}}$
\end{tabular}

\begin{tabular}{c}
\hline Expected no. of deaths \\
\hline 48.3 \\
32.2 \\
24.5 \\
16.1 \\
48.3 \\
11.4 \\
46.6 \\
14.8
\end{tabular}

\begin{tabular}{c}
\hline Observed no. of deaths \\
\hline \\
42 \\
23 \\
16 \\
25 \\
42 \\
10 \\
33 \\
21
\end{tabular}

\begin{tabular}{l}
\hline Standardised mortality ratio $(95 \% \mathrm{Cl})$ \\
\hline $0.87(0.63-1.18)$ \\
$0.72(0.45-1.07)$ \\
$0.65(0.37-1.06)$ \\
$1.56(1.01-2.30)$ \\
\\
$0.87(0.63-1.18)$ \\
$0.88(0.42-1.62)$ \\
$0.71(0.49-0.99)$ \\
$1.42(0.88-2.17)$ \\
\hline
\end{tabular}

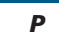

\subsection{1}

0.12

0.091

0.047

0.41

0.84

0.046

0.15

aSignificant difference between the groups $(P=0.011)$; bSignificant difference between the groups $(P=0.017)$.

NFPA, non-functioning pituitary adenoma; HCeq, hydrocortisone equivalents have been calculated as previously described (15, 16).

without, 0.88 (95\% CI: 0.68-1.12) and 0.87 (95\% CI: 0.63-1.18) respectively. Also, when separately analysing women, there was no difference in SMR between patients with and without secondary AI, 1.01 (95\% CI: 0.60-1.59) and 0.86 (95\% CI: 0.50-1.38) respectively. SMR for patients with an HCeq dose of $>20 \mathrm{mg}$ per day was higher (1.42; 95\% CI: 0.88-2.17) than that for patients with a daily HCeq dose of $20 \mathrm{mg}(0.71 ; 95 \% \mathrm{CI}$ : 0.49-0.99) $(P=0.017)$ (Table 3). Furthermore, SMR was also higher for patients receiving a daily $\mathrm{HCeq}$ dose of $>0.30-0.55 \mathrm{mg} / \mathrm{kg}(1.56$; 95\% CI: 1.01-2.30) compared with patients receiving a daily HCeq dose of $>0.25-0.30 \mathrm{mg} / \mathrm{kg}(0.65 ; 95 \% \mathrm{CI}$ : 0.37-1.06) $(P=0.011)$.

Internal analyses were also performed in order to adjust for confounding factors. Cox-regression, adjusted for age at the start of study, gender and radiotherapy, showed that patients receiving a daily HCeq dose of $>20 \mathrm{mg}$ had
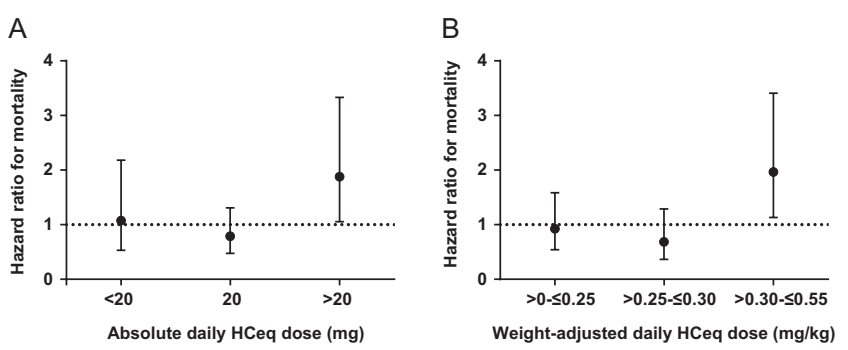

\section{Figure 1}

Hazard ratio with $95 \%$ confidence intervals for mortality in patients with non-functioning pituitary adenoma (NFPA) and secondary adrenal insufficiency. Treatment groups were based on absolute (A) and weight-adjusted (B) hydrocortisone equivalent $(\mathrm{HCeq})$ replacement doses and were compared to NFPA patients without secondary adrenal insufficiency. The analysis was adjusted for age at start of study, gender and radiotherapy. a significantly increased mortality compared to patients without GC replacement (HR: 1.88; 95\% CI: 1.06-3.33; $P=0.032$ ). In contrast, patients with a daily HCeq dose of $20 \mathrm{mg}$ and patients with $<20 \mathrm{mg}$ had mortality similar to patients without GC replacement (Fig. 1A). These results were consistent for weight-adjusted doses where patients receiving $>0.30 \mathrm{mg} / \mathrm{kg}$ of daily $\mathrm{HCeq}$ had an increased mortality (HR: 1.97; 95\% CI: 1.13-3.41; P=0.016) (Fig. 1B) compared to patients without GC replacement. Neither treatment with radiotherapy, nor gender had a significant effect on mortality. The HR for women was 1.5 (95\% CI: 0.92-2.63) in the Cox-regression investigating the total daily HCeq dose and 1.4 (95\% CI: 0.86-2.34) in the Coxregression investigating the weight-adjusted dose.

\section{Discussion}

In this study on an unselected population of 392 NFPA patients, we have shown that daily $\mathrm{HC}$ replacement doses above $20 \mathrm{mg}$ or $0.30 \mathrm{mg} / \mathrm{kg}$ in patients with secondary AI were associated with increased mortality compared to patients with lower doses and to patients without secondary AI. Patients with NFPA with daily doses of $\leq 20 \mathrm{mg}$ had, however, a mortality risk comparable to patients without GC replacement and to the general population.

This study is the first to show that daily HC doses already at $>20 \mathrm{mg}$ or $>0.30 \mathrm{mg} / \mathrm{kg}$ are associated with increased mortality. Previous studies have shown that patients with secondary AI receiving higher GC replacement doses conferred an independent risk of death in studies conducted among patients with acromegaly (>25 mg/day) and NFPA ( $\geq 30 \mathrm{mg} /$ day) $(4,12,13)$. Zueger et al. reported increased mortality with a RR of 4.0 (95\% CI: 1.07-14.85) for patients receiving daily $\mathrm{HC}$ 
doses of $\geq 30 \mathrm{mg}$ (4). A more recent study by O'Reilly et al. reported similar results with a RR 3.79 (95\% CI: 1.49_ 9.67) for hypopituitary patients receiving HC doses of $\geq 30 \mathrm{mg}$ (13). These findings support that higher doses for replacement may contribute to increased cardiovascular morbidity and mortality such as that seen in patients with Cushing's syndrome (18). O'Reilly et al. concluded that secondary AI (HR: 2.26; 95\% CI: 1.15-4.47), independent from dose, had a negative impact on mortality (13). However, we could not see an overall increased mortality in patients with secondary AI, only in those with higher GC replacement doses.

Several studies have demonstrated an excess mortality in hypopituitary patients, especially in women $(2,5)$. Due to the heterogeneity of the disease, the exact cause of this increased mortality is difficult to study. Risk of death is largely influenced by the underlying condition such as craniopharyngioma, a disease with mortality rate nearly 4 times that of other more benign causes of hypopituitarism $(2,19)$. Previous data are inconsistent in terms of the impact of pituitary radiation therapy on mortality $(20,21)$. This may, however, be influenced by the size and behaviour of the underlying tumour. Also, secondary AI, untreated gonadotropin deficiency, untreated growth hormone deficiency and the presence of diabetes insipidus have all been identified as independent factors of mortality in some but not all studies $(2,7,12$, $13,22,23)$.

The previously demonstrated excess mortality in patients with $\mathrm{AI}$ has been mainly attributable to cardiovascular, respiratory and infectious diseases as well as cancer $(1,2,24)$. It is likely that the degree of $\mathrm{AI}$ is of importance for outcome and that patients who are completely insufficient may be more vulnerable to intercurrent illness, whereas patients with partial ACTH deficiency may be over-treated under normal unstressed conditions using conventional replacement doses (25). Hence, inadequate treatment of hypocortisolism remains a significant cause of death during stressful events and intercurrent illness in patients with hypopituitarism (26). A possible explanation for the poor outcome in patients with $\mathrm{AI}$ receiving overly high doses of GC replacement is that excess GC exposure over time induces independent risk factors for cardiovascular disease such as diabetes mellitus, hypertension and obesity $(27,28,29)$.

A major strength of this study is the unselected cohort of patients diagnosed with NFPA within the same geographical area. To the best of our knowledge, this is the first study where SMR was compared between patients on different GC replacement doses in a cohort of patients without a high inherent excess mortality such as acromegaly or craniopharyngioma. In addition, the follow-up period was extensive with a mean observation time of more than 10 years. Also, patients were not only compared to the general population, but also to a group with the same underlying pituitary disease without GC replacement. Furthermore, all patients with high doses of GC due to non-endocrine diseases were excluded from the analysis. The limitations of this study are its retrospective design and that cumulative GC exposure over time was not available. Additionally, due to the limitations of the study size, effects of gender and radiotherapy on mortality cannot be ruled out.

In conclusion, we can show that NFPA patients with secondary AI with a daily HCeq replacement dose already higher than $20 \mathrm{mg}$ or $0.30 \mathrm{mg} / \mathrm{kg}$ have an increased mortality both when compared to patients with HCeq doses $\leq 20 \mathrm{mg}$ per day and in comparison with the background population. Our study also shows that daily replacement doses of $20 \mathrm{mg}$ HCeq or less do not result in any premature mortality. Previous studies together with our data highlight the importance of using replacement treatment that results in a physiological cortisol exposure to prevent an excess mortality.

\section{Declaration of interest}

D S O has been a consultant for Sandoz, Ipsen, Novartis and Pfizer. A G N has received lecture fees from Shire and Pfizer. G J has received speaker's honorarium from Eli Lilly, Merck Serono, Novartis, Novo Nordisk, Pfizer, Otsuka and Shire and has been a consultant for AstraZeneca, Merck Serono, Pfizer and Shire. C H, T H, E A, T S and O R have nothing to disclose.

\section{Funding}

This study was sponsored by the Swedish federal government under the ALF agreement on medical training and research. The sponsors did not take part in any manner in the design and conduct of the study, in the collection, management, analysis and interpretation of data, or in the writing and the decision to submit the manuscript.

\section{Author contribution statement}

All authors took part in the design of the study. C H and D S O performed the patient selection process. $\mathrm{C} \mathrm{H}$ and D S O have reviewed all the patient medical records. All authors contributed to the data interpretation and analysis and in writing and revision of the report. All authors are responsible for the integrity of the data and accuracy of the analysis, and all approved the final report.

\section{Acknowledgements}

The authors would like to express our gratitude to the staff at the Centre for Endocrinology and Metabolism at the Department of Endocrinology at Sahlgrenska University Hospital and to The National Board of Health and Welfare for their excellent collaboration. 


\section{References}

1 Rosen T \& Bengtsson BA. Premature mortality due to cardiovascular disease in hypopituitarism. Lancet 1990336 285-288. (doi:10.1016/0140-6736(90)91812-O)

2 Tomlinson JW, Holden N, Hills RK, Wheatley K, Clayton RN, Bates AS, Sheppard MC \& Stewart PM. Association between premature mortality and hypopituitarism. West Midlands Prospective Hypopituitary Study Group. Lancet 2001357 425-431. (doi:10.1016/S0140-6736(00)04006-X)

3 Gaillard RC, Mattsson AF, Akerblad AC, Bengtsson BA, Cara J, FeldtRasmussen U, Koltowska-Haggstrom M, Monson JP, Saller B, Wilton P et al. Overall and cause-specific mortality in GH-deficient adults on GH replacement. European Journal of Endocrinology of the European Federation of Endocrine Societies 2012166 1069-1077. (doi:10.1530/EJE-11-1028)

4 Zueger T, Kirchner P, Herren C, Fischli S, Zwahlen M, Christ E \& Stettler C. Glucocorticoid replacement and mortality in patients with nonfunctioning pituitary adenoma. Journal of Clinical Endocrinology and Metabolism 201297 E1938-E1942. (doi:10.1210/jc.2012-2432)

5 Olsson DS, Nilsson AG, Bryngelsson IL, Trimpou P, Johannsson G \& Andersson E. Excess mortality in women and young adults with nonfunctioning pituitary adenoma: a Swedish nationwide study. Journal of Clinical Endocrinology and Metabolism 2015100 2651-2658. (doi:10.1210/jc.2015-1475)

6 Olsson DS, Bryngelsson IL \& Ragnarsson O. Time trends of mortality in patients with non-functioning pituitary adenoma: a Swedish nationwide study. Pituitary 201720 218-224. (doi:10.1007/s11102-016-0764-8)

7 Pappachan JM, Raskauskiene D, Kutty VR \& Clayton RN. Excess mortality associated with hypopituitarism in adults: a meta-analysis of observational studies. Journal of Clinical Endocrinology and Metabolism 2015100 1405-1411. (doi:10.1210/jc.2014-3787)

8 Olsson DS, Bryngelsson IL \& Ragnarsson O. Higher incidence of morbidity in women than men with non-functioning pituitary adenoma: a Swedish nationwide study. European Journal of Endocrinology of the European Federation of Endocrine Societies 2016175 55-61. (doi:10.1530/EJE-16-0173)

9 Esteban NV, Loughlin T, Yergey AL, Zawadzki JK, Booth JD, Winterer JC \& Loriaux DL. Daily cortisol production rate in man determined by stable isotope dilution/mass spectrometry. Journal of Clinical Endocrinology and Metabolism 199172 39-45. (doi:10.1210/jcem-72-1-39)

10 Kerrigan JR, Veldhuis JD, Leyo SA, Iranmanesh A \& Rogol AD. Estimation of daily cortisol production and clearance rates in normal pubertal males by deconvolution analysis. Journal of Clinical Endocrinology and Metabolism 199376 1505-1510. (doi:10.1210/jc.76.6.1505)

11 Filipsson H, Monson JP, Koltowska-Haggstrom M, Mattsson A \& Johannsson G. The impact of glucocorticoid replacement regimens on metabolic outcome and comorbidity in hypopituitary patients. Journal of Clinical Endocrinology and Metabolism 200691 3954-3961. (doi:10.1210/jc.2006-0524)

12 Sherlock M, Reulen RC, Alonso AA, Ayuk J, Clayton RN, Sheppard MC, Hawkins MM, Bates AS \& Stewart PM. ACTH deficiency, higher doses of hydrocortisone replacement, and radiotherapy are independent predictors of mortality in patients with acromegaly. Journal of Clinical Endocrinology and Metabolism 200994 4216-4223. (doi:10.1210/jc.2009-1097)

13 O'Reilly MW, Reulen RC, Gupta S, Thompson CA, Dineen R, Goulden EL, Bugg G, Pearce H, Toogood AA, Gittoes NJ et al. ACTH and gonadotropin deficiencies predict mortality in patients treated for nonfunctioning pituitary adenoma: long-term follow-up of 519 patients in two large European centres. Clinical Endocrinology 201685 748-756. (doi:10.1111/cen.13141)

14 Mah PM, Jenkins RC, Rostami-Hodjegan A, Newell-Price J, Doane A, Ibbotson V, Tucker GT \& Ross RJ. Weight-related dosing, timing and monitoring hydrocortisone replacement therapy in patients with adrenal insufficiency. Clinical Endocrinology 200461 367-375. (doi:10.1111/j.1365-2265.2004.02106.x)

15 Liddle GW. Clinical pharmacology of the anti-inflammatory steroids. Clinical Pharmacology and Therapeutics 19612 615-635. (doi:10.1002/ cpt196125615)

16 Boland EW. Antirheumatic effects of hydrocortisone (free alcohol), hydrocortisone acetate, and cortisone (free alcohol) as compared with cortisone acetate; results from oral administration in patients with rheumatoid arthritis. British Medical Journal 19521 559-564. (doi:10.1136/bmj.1.4758.559)

17 Altman DG \& Bland JM. Interaction revisited: the difference between two estimates. BMJ 2003326 219. (doi:10.1136/bmj.326.7382.219)

18 Sherlock M, Ayuk J, Tomlinson JW, Toogood AA, Aragon-Alonso A, Sheppard MC, Bates AS \& Stewart PM. Mortality in patients with pituitary disease. Endocrine Reviews 201031 301-342. (doi:10.1210/er.2009-0033)

19 Olsson DS, Andersson E, Bryngelsson IL, Nilsson AG \& Johannsson G. Excess mortality and morbidity in patients with craniopharyngioma, especially in patients with childhood onset: a population-based study in Sweden. Journal of Clinical Endocrinology and Metabolism 2015100 467-474. (doi:10.1210/jc.2014-3525)

20 Ayuk J \& Stewart PM. Mortality following pituitary radiotherapy. Pituitary 200912 35-39. (doi:10.1007/s11102-007-0083-1)

21 Brada M, Ashley S, Ford D, Traish D, Burchell L \& Rajan B. Cerebrovascular mortality in patients with pituitary adenoma. Clinical Endocrinology 200257 713-717. (doi:10.1046/j.1365-2265.2002.01570.x)

22 Hannon MJ, Crowley RK, Behan LA, O'Sullivan EP, O'Brien MM, Sherlock M, Rawluk D, O'Dwyer R, Tormey W \& Thompson CJ. Acute glucocorticoid deficiency and diabetes insipidus are common after acute traumatic brain injury and predict mortality. Journal of Clinical Endocrinology and Metabolism 201398 3229-3237. (doi:10.1210/jc.2013-1555)

23 Olsson DS, Trimpou P, Hallen T, Bryngelsson IL, Andersson E, Skoglund T, Bengtsson BA, Johannsson G \& Nilsson AG. Life expectancy in patients with pituitary adenoma receiving growth hormone replacement. European Journal of Endocrinology 2017176 67-75. (doi:10.1530/EJE-16-0450)

24 Bergthorsdottir R, Leonsson-Zachrisson M, Oden A \& Johannsson G. Premature mortality in patients with Addison's disease: a populationbased study. Journal of Clinical Endocrinology and Metabolism 200691 4849-4853. (doi:10.1210/jc.2006-0076)

25 Agha A, Liew A, Finucane F, Baker L, O'Kelly P, Tormey W \& Thompson CJ. Conventional glucocorticoid replacement overtreats adult hypopituitary patients with partial ACTH deficiency. Clinical Endocrinology 200460 688-693. (doi:10.1111/j.1365-2265.2004.02035.x)

26 Burman P, Mattsson AF, Johannsson G, Hoybye C, Holmer H, Dahlqvist P, Berinder K, Engstrom BE, Ekman B, Erfurth EM et al. Deaths among adult patients with hypopituitarism: hypocortisolism during acute stress, and de novo malignant brain tumors contribute to an increased mortality. Journal of Clinical Endocrinology and Metabolism 201398 1466-1475. (doi:10.1210/jc.2012-4059)

27 Andrews RC \& Walker BR. Glucocorticoids and insulin resistance: old hormones, new targets. Clinical Science 199996 513-523. (doi:10.1042/cs0960513)

28 Plotz CM, Knowlton AI \& Ragan C. The natural history of Cushing's syndrome. American Journal of Medicine 195213 597-614. (doi:10.1016/0002-9343(52)90027-2)

29 Werumeus Buning J, van Faassen M, Brummelman P, Dullaart RP, van den Berg G, van der Klauw MM, Kerstens MN, Stegeman CA, Muller Kobold AC, Kema IP et al. Effects of hydrocortisone on the regulation of blood pressure: results from a randomized controlled trial. Journal of Clinical Endocrinology and Metabolism 2016101 3691-3699. (doi:10.1210/jc.2016-2216)

Received 27 April 2017

Revised version received 3 June 2017

Accepted 8 June 2017 